\title{
LA INTERVERSIÓN DE TÍTULO EN EL DERECHO ARGENTINO
}

[Possession, its types and mutations in the Argentine Law]

\section{Guillermo GAPEL RedCozUB*}

\begin{abstract}
RESUMEN
El derecho argentino reconoce dos clases de relaciones de poder, consistentes en vínculos de hecho con las cosas cuya existencia no requiere de antecedentes jurídicos: la posesión y la tenencia. El mecanismo por el cual un sujeto puede pasar de una relación de poder a otra se denomina interversión de titulo, y el presente trabajo analiza los elementos y condiciones necesarios para que se produzca este fenómeno de acuerdo a la normativa del Código Civil y Comercial de la Nación y a la jurisprudencia actual.

Palabras clave

Interversión - Posesión - Tenencia - Relaciones de Poder.
\end{abstract}

\section{ABSTRACT}

The Argentine Law recognizes that an individual can exercise her power over a thing (possession in a broad sense) and states that this relationship creates certain consequences without paying attention to its legal background or the entitlements at stake. There are two types of power relationships named "posesión" and "tenencia", and the mechanism that allows a person to move from one type to the other is called "interversión". The article studies what are the legal requirements for "interversión" to take place.

\section{KEY WORDS}

Power Relationships - Possession

- Types of Possession - Adverse Possession.

RECIBIDO el 27 de marzo y ACEPTAdo el 31 de octubre de 2017

* Master of Laws (LLM), Harvard Law School. Profesor Titular de Derechos Reales en la Facultad de Derecho de la Universidad Nacional del Nordeste (Argentina).Correo electrónico: guillermogapel@gmail.com 


\section{INTRODUCCIÓN}

El Código Civil y Comercial de la Nación (CCCN $)^{1}$ enumera y define las relaciones de poder que pueden existir entre una persona y una cosa en el ordenamiento jurídico argentino, y que son la posesión y la tenencia.

Ambas figuras se consideran eminentemente estados de hecho, es decir, situaciones fácticas para cuya existencia no se requiere de un antecedente jurídico.

Estos estados de hecho generan una serie consecuencias jurídicas relevantes: dan lugar a acciones de defensa de la relación de poder y producen un conjunto de efectos que el Código puntualiza con significativo grado de detalle (arts. 1932 a 1940 del CCCN).

A lo largo de las últimas décadas se ha ido produciendo una ampliación de la protección legal de la tenencia, hasta prácticamente asimilarla a la tutela que recibe la figura de la posesión. Esto es así al punto tal que hoy las defensas se encuentran reguladas en sus aspectos centrales directamente en forma conjunta (en los arts. 2238, 2241 y 2242 del CCCN).

La diferencia más importante que ha subsistido, entonces, radica en que la posesión, cuando reúne ciertos elementos, permite adquirir un derecho real sobre la cosa (modo que recibe el nombre de usucapión o prescripción adquisitiva), mientras que la tenencia jamás conducirá al derecho de propiedad.

Esto torna especialmente interesantes los estudios referidos a cómo pasar de una clase de relación de poder a otra, puesto que cotidianamente se plantean ante los tribunales casos en que los justiciables aseguran haber adquirido el dominio de un inmueble por usucapión, a pesar de haber iniciado la relación de poder con la cosa en carácter de tenedores. Por ejemplo, guardianes o custodios de una vivienda, o antiguos inquilinos, todos ellos tenedores por definición, que aseveran ante el tribunal que en algún momento se convirtieron en poseedores y luego también en dueños del inmueble.

El mecanismo legal para mutar de especie de relación de poder se denomina "interversión de título" y a lo largo del artículo veremos cuáles son sus elementos, clases y sus condiciones de procedencia, prestando atención a las pautas brindadas por la jurisprudencia y a la luz de la normativa del nuevo Código Civil y Comercial argentino. La reciente sanción de este cuerpo legal ha abierto una oportunidad inigualable para reexaminar los

1 Aprobado por Ley Nacional N. 26.994 del 01/10/14, con vigencia desde el 01/08/2015. 
institutos del derecho privado con renovado espíritu crítico, y el presente trabajo se propone avanzar en tal sentido.

\section{LAS RELACIONES DE PODER}

En el Derecho civil argentino la posesión es considerada un hecho ${ }^{2}$, fijando con ello el legislador una postura que se aparta tajantemente de las teorías que le atribuyen calidad de derecho ${ }^{3}$.

Junto a la tenencia conforman la categoría jurídica que recibe el nombre de "relaciones de poder" (antes llamadas "relaciones reales" por la doctrina) y están específicamente reguladas en el Libro Cuarto -Título Segundo- del CCCN. La categoría no tiene definición normativa, pero los autores concuerdan en remarcar que estas relaciones refieren a situaciones fácticas, poderes que se ejercen de hecho sobre una cosa con independencia de cualquier respaldo, antecedente o investidura jurídica ${ }^{4}$.

La caracterización detallada de estos institutos es una tarea de gran envergadura que excedería largamente a la finalidad del artículo, no obstante lo cual haremos una presentación breve del tema destinada esencialmente a brindar precisiones conceptuales y terminológicas para quienes no están familiarizados con estos conceptos o bien pertenecen a tradiciones jurídicas donde se les asignan significados distintos.

El art. 1909 CCCN establece que "Hay posesión cuando una persona,

2 Aunque las polémicas en torno a la figura lejos están de apaciguarse: "La posesión es, sin duda, la institución más controvertida del Derecho civil. En efecto, todo cuanto se vincula con ella ha sido y es motivo de discusión: el concepto, la etimología de la palabra, el origen, el número de elementos y su caracterización, la naturaleza jurídica, el fundamento de su protección, las funciones que cumple, los principios que rigen su adquisición, su conservación y su pérdida, los efectos que produce", señala Arean, Beatriz, Derechos Reales (6. ${ }^{a}$ edición, Buenos Aires, Hammurabi, 2003) I, p. 115.

${ }^{3}$ Una descripción de la posición que han adoptado numerosos autores nacionales en esta discusión durante la vigencia del Código Civil anterior puede hallarse en Musto, Néstor Jorge, Derechos Reales (Buenos Aires, Astrea, 2007) I, pp. 167-169.

${ }^{4}$ Así la conceptualizan Kiper, Claudio, en Lorenzetti, Ricardo (director), Código Civily Comercial de la Nación Comentado (Santa Fe, Rubinzal Culzoni, 2015) IX, pp. 93-94; Pettis, Christian - Rosembrock, Javier, en Bueres, Alberto (director), Código Civily Comercial de la Nación (Buenos Aires, Hammurabi, 2014), II, pp. 262-263; CAUsse, Federico - Pettis, Christian, en Herrera, Marisa - Caramelo, Gustavo - Picasso, Sebastián (directores), Código Civil y Comercial de la Nación Comentado ( $1^{\circ}$ edición, Buenos Aires, Infojus, 2015), V, pp. 39-40, ratificando todos ellos que las relaciones de poder reguladas en el CCCN son las mismas que la doctrina previamente titulaba como relaciones fácticas, reales o materiales. 
por sí o por medio de otra, ejerce un poder de hecho sobre una cosa, comportándose como titular de un derecho real, lo sea o no."

El análisis convencional de la norma distingue en ella dos elementos complementarios: el corpus y el animus domini. Siguiendo en la materia las ideas de Savigny, Arean explica que el corpus "consiste (...) en la posibilidad de hacer de la cosa lo que se quiera y de defenderla de toda injerencia extraña", y que el animus domini "consiste en la intención de ejercer el derecho de propiedad". Mariani de Vidal enseña que el corpus "es la posibilidad de disponer físicamente de la cosa en cualquier momento, independientemente del poder de disponer por actos jurídicos de ella"77 y que el animus domini "surgiría cuando el que tiene efectivamente la cosa en su poder (corpus) no reconoce en otra persona fuera de sí mismo, un señorío superior (animus domini)'

Toda vez que tengamos un sujeto ejerciendo un poder de hecho sobre una cosa, comportándose como titular de un derecho real sobre ella (generalmente, como el dueño), la relación será calificada de posesoria. Esto vale tanto para quien ha adquirido legítimamente la cosa como para quien la ha robado o la ha usurpado, puesto que la presencia o la ausencia de algún antecedente jurídico no es trascendente para la existencia de la relación.

En cambio, se entiende que "Hay tenencia cuando una persona, por sí o por medio de otra, ejerce un poder de hecho sobre una cosa, y se comporta como representante del poseedor.", conforme lo establece el art. 1910 del CCCN. Causse y Pettis manifiestan que la tenencia contiene al corpus pero carece de animus domini, y que el tenedor, aunque tenga la posibilidad de disponer físicamente de la cosa, reconoce que la posesión pertenece a otra persona y se conduce como su representante. Concluyen en que esta relación es de categoría inferior a la posesión y por tanto es natural que sus efectos sean menos importantes 9 .

Recapitulando, en el Derecho argentino la posesión y la tenencia constituyen conceptos técnico-jurídicos distintos. Si bien ambas son clases de relaciones de poder, sus regímenes regulatorios difieren, en especial, respecto de los efectos de cada una. En el apartado siguiente trataremos la cuestión atinente a las circunstancias o condiciones mediante las cuales un sujeto puede convertir su clase de relación de poder en otra.

5 Arean, Beatriz, cit. (n. 2), p. 122.

${ }^{6}$ Arean, Beatriz, cit. (n. 2), p. 122.

${ }^{7}$ Mariani de Vidal, Marina, Derechos Reales (8. ${ }^{a}$ edición, Buenos Aires, Zavalía, 2009) I, p. 114.

${ }^{8}$ Mariani de Vidal, Marina, cit. (n. 7), p. 115.

${ }^{9}$ Causse, Federico y PetTis, Christian, cit. (n. 4), p. 41. 


\section{LA INTERVERSIÓN DE TÍTULO}

Explica Mariani de Vidal que la interversión "es el cambio de la causa o título en virtud del cual se está poseyendo o teniendo una cosa"10 y que el principio general en la materia es el de la inmutabilidad de la relación de poder, es decir, opera la regla de que nadie puede por sí mismo ni por el mero transcurso del tiempo cambiar la causa de su posesión ${ }^{11}$.

Esta regla proviene del Derecho romano, en donde se la empleó en un primer momento con la finalidad específica de evitar que se cometieran una serie de abusos en perjuicio de los herederos y acreedores prendarios (desnaturalizando las figuras de la usucapio pro herede lucrativa y de la usureceptio $)^{12}$. Posteriormente adquiere carácter general y se vuelve aplicable a todo tipo de supuestos.

El Código Civil argentino (C.Civ. ${ }^{13}$ incluyó esta regla en su versión tradicional y en forma expresa en el art. 2353, positivizando una norma que se integraba además con las previsiones del art. $2458^{14}$.

Cabe destacar que este principio de inmutabilidad de la causa de la

${ }^{10}$ Mariani de Vidal, Marina, cit. (n. 7), p. 166, en igual sentido véase Musto, Néstor Jorge, cit. (n. 3), p. 163; Clerc, Carlos, Derechos reales e intelectuales (Buenos Aires, Hammurabi, 2007) I, pp. 122-124.

${ }^{11}$ La voz "causa" es empleada en este contexto en el sentido de antecedente jurídico que engendra el derecho. Véase Perrotti, Pedro, Los Derechos Reales y la Teoría General de la Posesión (Corrientes, Moglia, 2003), p. 65.

${ }^{12}$ Musto, Néstor Jorge, cit. (n. 3), p. 164 refiere que la usucapio pro berede fue instituida a fin de impulsar al heredero a aceptar la herencia lo antes posible, permitiendo usucapir a quien lograse poseer los bienes relictos por el plazo de un año. Los arrendatarios, comodatarios y depositarios, frente a la inacción del heredero, intentaban valerse de la figura para obtener la propiedad de la cosa. A su vez, la usureceptio consistía en la facultad de recuperar una cosa que se había enajenado fiduciariamente mediante el uso o posesión por un término breve y sin necesidad de justo título ni buena. La usureceptio se prestaba para que los deudores prendarios emplearan artificios para hacerse con el uso de la cosa dada en garantía e invocaran posteriormente y con malicia que se había producido su readquisición.

13 Aprobado por la Ley Nacional No 340 del 29/09/1869, con vigencia desde el 01/01/1871 hasta el 31/07/2015. Fue derogado por la Ley Nacional N. 26994 del 01/10/14.

${ }^{14} \mathrm{El}$ art. 2353 del C. Civ. disponía que "Nadie puede cambiar por sí mismo ni por el transcurso del tiempo, la causa de su posesión. El que comenzó a poseer por sí y como propietario de la cosa, continúa poseyendo como tal, mientras no se pruebe que ha comenzado a poseer por otro. El que ha comenzado a poseer por otro, se presume que continúa poseyendo por el mismo título, mientras no se pruebe lo contrario." El art. 2458 del C. Civ. establecía que "Se pierde la posesión cuando el que tiene la cosa a nombre del poseedor, manifiesta por actos exteriores la intención de privar al poseedor de disponer de la cosa, y cuando sus actos producen ese efecto." 
relación de poder jamás se consideró absoluto, sino que la interpretación de los artículos citados permitió distinguir dos escenarios en los cuáles el ordenamiento reconocía la posibilidad de que la especie de relación varíe ${ }^{15}$.

En primer lugar, se consideró válido que la causa de la relación de poder se modifique existiendo acuerdo de partes, lo que da lugar a las figuras denominadas constituto posesorio y traditio brevi manu ${ }^{16 .}$

El constituto posesorio "consiste en la transformación de una relación de posesión en una relación de tenencia, operada sin que haya ocurrido la transmisión o entrega real de la cosa. Así, si el propietario de una casa la vende y continúa sin embargo habitando en ella, en calidad de inquilino, ha dejado de ser poseedor para convertirse en simple tenedor. Una relación posesoria animo domini se ha convertido en una relación de detención"17.

En la traditio brevi manu, en cambio, "el tenedor pasa a ser poseedor de la cosa. Ello comprende dos supuestos: cuando la cosa es tenida a nombre del propietario y éste, por un acto jurídico, pasa el dominio a su nombre, y cuando alguien posee la cosa a nombre del propietario y pasa a poseerla por otro" 18 .

En sendos casos (constituto y traditio), regulados hoy en el art. 1923 del CCCN, se considera que hay modificación de la especie de relación aun cuando no se produzca transmisión o entrega de la cosa, entendiéndose que la celebración de un acto jurídico bilateral produce una interversión bilateral o lícita ${ }^{19}$.

En segundo lugar, el ordenamiento permitió que la interversión también pueda ser producida por actos unilaterales que revistan ciertas condiciones

${ }^{15}$ Una explicación pormenorizada respecto del carácter relativo de la regla puede verse en Fuster, Gabriel, La necesaria "re-significación" de la interversión de título. La dinámica funcional del corpus y el animus posesorios, en Revista La Ley Córdoba (2013), p. 1184.

${ }^{16}$ El constituto y la traditio nacen en el derecho romano por razones prácticas, prescindiéndose de la tradición efectiva por convertirse en estos casos en una formalidad inútil, indica BorDA, Guillermo, Tratado de Derecho Civil-Derechos Reales (2. ${ }^{\mathrm{a}}$ edición, Buenos Aires, Perrot, 1978), I, p. 105.

${ }^{17}$ Gschwind, Francisco, El constituto posesorio en el Código Civil Argentino, ahora, en Alterini, Jorge Horacio (editor), Derecho notarial, registral e inmobiliario (Buenos Aires, La Ley, 2012), IV, p. 165.

${ }^{18}$ Causse, Federico - Pettis, Christian, cit. (n. 4), p. 54.

${ }^{19}$ Se opone a ello Ventura alegando (en posición minoritaria) que la interversión no puede admitir antecedentes jurídicos, debe ser siempre unilateral. Sostiene que es "un supuesto "patológico", cuya rareza y principal interés estriba en la posibilidad de cambiar unilateralmente la relación real de que se trate, y tanto más interesante se hace si dicho cambio o alteración se realiza frente a la oposición del poseedor anterior $[. .$.$] no hay interversión cuando se ha elaborado una nueva causa$ de adquisición por acuerdo voluntario con el anterior poseedor [...]". Véase VentuRA, Gabriel, La interversión de título, en Revista La Ley Córdoba (2001), p. 261. 
puntuales: deben consistir en manifestaciones de la voluntad de convertirse en poseedor, exteriorizadas con suficiente potencia como para excluir al anterior poseedor de la posibilidad de disponer de la cosa. Esta vía fue conocida como interversión unilateral o ilícita.

En el CCCN se mantuvo la regla de la inmutabilidad de la causa (con sus excepciones) en el art. 1915, en el que se mejora ligeramente su redacción, y más importante aún, se concentran los componentes de una figura que antes se hallaban dispersos en distintas previsiones legales, facilitando su comprensión y aplicación. Este artículo estipula que "Nadie puede cambiar la especie de su relación de poder, por su mera voluntad, o por el solo transcurso del tiempo. Se pierde la posesión cuando el que tiene la cosa a nombre del poseedor manifiesta por actos exteriores la intención de privar al poseedor de disponer de la cosa, y sus actos producen ese efecto" ${ }^{\text {"20 }}$.

De esta manera, destaca Gurfinkel, la relación de poder adquiere estabilidad y queda fijada en y desde el momento de su constitución ${ }^{21}$.

Papaño, Kiper, Dillon y Causse afirman que existen supuestos adicionales de interversión, y que a los ya mencionados se pueden agregar la interversión por sentencia (cuando un dueño continua ocupando la cosa luego de que por sentencia se anulase su título o se le negase el derecho a poseerla, convirtiéndose en tenedor por decisión judicial) y la interversión por participación de tercero (cuando por error el tenedor celebra un acto que lo convertiría en poseedor pero lo realiza con persona no legitimada al efecto) $)^{22}$.

De las clases de interversiones citadas la que reviste mayor interés académico y práctico es, sin dudas, la que la doctrina denomina indistintamente unilateral o ilícita ${ }^{23}$.

${ }^{20}$ En el Derecho Chileno también se aplica la regla de la inmutabilidad de la causa (art. 716 C.Civ.), aunque se admite la transformación de la posesión en mera tenencia (arts. 684 inc. $5^{\circ}$ y 2494 C. Civ), y de la mera tenencia en posesión (arts. 716, 2510 regla $3^{\mathrm{a}}$ y 730 C. Civ.).

${ }^{21}$ Gurfinkel de Wendy, Lilian, Derechos Reales (2. ${ }^{a}$ edición, Buenos Aires, Abeledo Perrot, 2016), I, p. 179.

${ }^{22}$ Papaño, Ricardo - Kiper, Claudio - Dillon, Gregorio - Causse, Jorge, Dere-

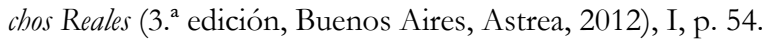

${ }^{23} \mathrm{Si}$ bien es cierto en que la gran mayoría de los casos las interversiones que se producen en virtud de la voluntad de un solo sujeto (y de allí, "unilaterales") serán al mismo tiempo ilícitas (porque violarán los derechos del intervertido), corresponde distinguir que en ciertas situaciones las interversiones unilaterales pueden configurar actos lícitos. Por ejemplo, cuando un poseedor que adquirió la cosa mediando violencia efectúa un acto de reconocimiento a favor del propietario despojado, ofreciendo comprársela o alquilársela. Este reconocimiento, que lo convierte automáticamente en simple tenedor, puede ser considerado como un acto unilateral 
El supuesto más frecuente de esta clase de mutación tiene lugar cuando un tenedor incurre en abuso de confianza, desapoderando al sujeto que en un primer momento le entregó voluntariamente la cosa en el marco de un contrato que genera el deber de restitución, como la locación, el comodato o el depósito. Así, se convierte en poseedor ilegítimo, de mala fe y vicioso. Ilegítimo, por cuanto la relación de poder que pasa a ejercer no tiene sustento objetivo en un derecho constituido de conformidad a las leyes. Es de mala fe, puesto que este poseedor conoce fehacientemente que ha variado su condición sin respaldo jurídico suficiente. Y, finalmente, su posesión es viciosa en razón de que se ha originado en un vicio específicamente tipificado en el Código tanto para cosas muebles como para inmuebles, que es el abuso de confianza (art. 1921).

Esta clase de interversión cobra destacada relevancia generalmente en los procesos judiciales de usucapión y de desalojo.

Respecto de los juicios de usucapión, la sentencia declarativa de prescripción adquisitiva debe fijar la fecha en la cual se considera cumplido el plazo de prescripción y operada en consecuencia la adquisición del derecho real (art. 1905 CCCN), lo que equivale a decir que la sentencia debe necesariamente determinar cuándo y cómo se originó la posesión del actor. Y siempre que la posesión se haya iniciado en calidad de tenedor, lo que sucede con cierta frecuencia, devendrá imprescindible discernir si en el caso particular se produjo una interversión unilateral. Quedan comprendidos aquí los supuestos de antiguos empleados (guardianes de inmuebles) e inquilinos que han permanecido ocupando la cosa durante muchos años, y también los casos de convivientes o cónyuges supérstites que manifiestan haberse convertido en poseedores luego del deceso de su pareja, e inclusive los de herederos que invocan la figura en perjuicio de otros sucesores (hipótesis esta última de una interversión de co-poseedor a poseedor "exclusivo").

En cuanto a los desalojos, una de las defensas empleadas con asiduidad por los demandados es la alegación de ser poseedores. Esto encuentra fundamento en que los tribunales atribuyen al proceso de desalojo un objeto especial, otorgándole legitimación pasiva solamente a tenedores y no a poseedores. Por ende, los magistrados entienden que todo debate en torno a la posesión excede del margen de conocimiento propio y acotado que caracteriza a dichos procesos y debe ventilarse en acciones posesorias o reales ${ }^{24}$. Es en este punto donde nuevamente la interversión adquiere

lícito. Por este motivo, quizá sea conveniente emplear exclusivamente el nombre de interversión unilateral para esta clase de supuestos.

24 "La acción de desalojo no corresponde contra el poseedor, ni por la naturaleza u objeto es idónea para obtener la recuperación del inmueble poseído por otro, 
significativa trascendencia, debiendo acreditar quienes han accedido a la cosa como tenedores que han mutado su condición a la de poseedores para que la demanda sea desestimada.

En virtud de su destacado interés teórico y práctico a continuación centraremos el análisis en esta particular clase de mutación de relación de poder.

\section{LA INTERVERSIÓN UNILATERAL}

En toda interversión, como condición necesaria y por definición, el sujeto debe partir de una especie de relación de poder para llegar a otra. En el momento inicial la persona es, por caso, tenedora, y luego deviene poseedora. Esto excluye de la figura todos aquellos supuestos en los cuales el sujeto adquiere una relación de poder en forma originaria, es decir, sin que se verifiquen antecedentes de ejercicio de poder respecto de la cosa. Así, por ejemplo, una persona que decide ocupar de manera violenta un inmueble sobre el que jamás había ejercido poder alguno no podrá ser considerado intervertor de título: no hay cambio de causa, no hay mutación, sino que solo existe una única causa de detentación.

Además de la existencia de dos especies de relación de poder (la inicial y la final), la interversión unilateral exige del sujeto que pretender intervertir: i) actos exteriores que manifiesten la intención de privar al poseedor de la disposición de la $\cos ^{25}$, ii) que, mediante estos actos, logre su finalidad de exclusión, vale decir, que se produzca el "efecto privación o exclusión".

La Corte Suprema de Justicia de la Nación (CSJN), en su último precedente en la materia, caracterizó a los actos exteriores de la siguiente manera: "La interversión requiere asi de actos de oposición y no de meras expresiones verbales, que sean lo suficientemente precisos para significar la voluntad del tenedor de excluir alposeedor, y lo suficientemente graves para poner en conocimiento de la situación al poseedor, para que éste pueda hacer valer sus derechos.

El acto de oposición es al mismo tiempo un acto de afirmación de la posesión propia

cualquiera sea el vicio que pudiera afectar esta posesión. No interesa por lo tanto en este juicio si la posesión es legítima o ilegítima, de buena o de mala fe; todo debate sobre el particular es extraño al juicio de desalojo". Síntesis al fallo del 15/06/95 de la Cámara Civil y Comercial de Morón (Provincia de Buenos Aires), Sala II, citado en Arean, Beatriz, Juicio de Desalojo (Buenos Aires, Hammurabi, 2004), p. 300. Esta importante línea jurisprudencial fue iniciada con el Fallo Plenario de la Cámara Nacional de Apelaciones de Paz (Capital Federal) del 15 de septiembre de 1960 dictado en autos "Monti, Atilio, Sucesión c/ Palacios de Buzzoni, Danila Silvia s/ Desalojo.

25 "Esos actos no deben dejar la menor duda que tienen por objeto privarlo de su posesión al actual poseedor", ha recalcado CORnejo, Américo, Interversión del título por el comodatario, en Revista La Ley (2013), p. 387. 
y de negación de la posesión ajena. Por otra parte, el acto de oposición debe ser público, en el sentido de que deben llegar a conocimiento del que sufre la interversión.

En este sentido, no son suficientes las meras declaraciones de voluntad, pues lo que debe exteriorizarse son hechos materiales. Es indispensable una manifiesta rebelión contra el titulo actual y contra el poseedor a nombre de quien ocupaba la cosa $[\ldots]^{26}$.

En cuanto al "efecto exclusión", la CSJN también aclaró que su alcance trasciende la simple inacción del afectado: "[...] no basta con que se acredite un relativo desinterés por el inmueble por parte de los demandados, sino que es necesaria la cabal demostración de los actos posesorios efectuados por quien pretende usucapir y que sean lo suficientemente idóneos como para poner al propietario, que debe haber tenido conocimiento de ellos, en el trance de hacer valer por la vía que corresponde los derechos que le han sido desconocidos" ${ }^{27}$.

En esta inteligencia, se habría llegado a exigir como recaudo de procedencia que el afectado intente recuperar la posesión de la cosa, que se coloque en situación de poder ser repelido por el intervertor para que pueda producirse la exclusión ${ }^{28}$. Bajo este criterio, si el afectado no tomara medidas tendientes a recuperar su posesión, aunque sospeche, conozca o deba conocer los actos materiales efectuados por el intervertor, lo privaría de la posibilidad de intervertir por ausencia del "efecto exclusión".

Ahora, pese a las precisiones ofrecidas por los tribunales respecto de los presupuestos de la interversión unilateral, la doctrina nacional no le ha prestado especial atención a la tarea de su sistematización, por lo que algunas aristas del fenómeno permanecen aún un tanto oscuras. A continuación formularemos algunas reflexiones que podrían resultar de interés para profundizar la comprensión de la figura, o cuanto menos para incentivar al debate.

Una primera pregunta que cabría hacerse es la siguiente: ¿qué califica-

${ }^{26}$ Corte Suprema de Justicia de la Nación (Argentina), Sentencia del 3 de junio de 2014 dictada en autos "Mimica, Ricardo Juan y otro c/ Tierra del Fuego, Antártida e Islas del Atlántico Sur, Provincia de s/ Usucapión”" (Considerando 13). En la idéntica línea de razonamiento el mismo tribunal se expresó en la Sentencia del 4 de mayo de 1993, dictada en autos "La Rinconada S.A. (en liquidación) c/ Estado Nacional s/ Nulidad de Resolución" (Considerando 23), que sigue el criterio expresado en la Sentencia del 11 de junio de 1962 dictada en autos "Cornet D'Hunval, Marcelo c/ Santa Cruz, la Provincia de s/ Posesión Treintañal” (Considerando 10).

${ }^{27}$ Corte Suprema de Justicia de la Nación (Argentina), Sentencia del 7 de octubre de 1993 dictada en autos "Glastra S.A.C. e I. c/ Estado Nacional y otros s/ Prescripción Adquisitiva”, Considerando 14.

${ }^{28}$ Superior Tribunal de Justicia de la Provincia de Corrientes (Argentina), Sentencia del 27 de noviembre del 2008 dictada en autos "Rodríguez Adriano c/ Alberto Tránsito Savaresse s/ Reivindicación” (Considerando XI). 
ción jurídica merecen estos "actos exteriores”? ¿son "actos posesorios" o son otra clase de actos?

Recordemos que los actos posesorios están definidos en el art. 1928 CCCN como actos de apoderamiento que se realizan sobre una cosa, dando la norma una serie de ejemplos de conductas que constituyen actos posesorios.

La importancia de los actos posesorios en materia de relaciones de poder y en el ámbito de los derechos reales es capital: en una tradición jurídica que al sancionar su primer Código Civil (1869) adhirió a la teoría subjetiva de la posesión ${ }^{29}$, estos actos configuran la principal (si no la única) manera de acreditar la existencia de animus domini en el poseedor. No habría forma de descubrir la presencia de ánimo de dueño si este no pudiera deducirse a partir de ciertos actos que realiza un sujeto. Huelga señalar que sin un mecanismo de prueba de la presencia de animus domini el esquema completo de la teoría subjetiva de la posesión se desmoronaría.

Los actos posesorios también constituyen el objeto central de la prueba en un proceso de usucapión, en el cual el usucapiente debe acreditar que ha poseído la cosa en forma ostensible, continua e ininterrumpida por el plazo de ley (arts. 1900, 2545 y 2546 CCCN). Y aquí nuevamente, la única forma de demostrarlo será mediante la comprobación de que el usucapiente ha efectuado suficientes actos posesorios.

Por su trascendencia para sostener en pie a la teoría subjetiva de la posesión, y por su papel esencial en los procesos de adquisición de derechos reales mediante usucapión, los actos posesorios se erigen como un pilar del sistema de relaciones de poder y de derechos reales.

Para Ventura, los actos exteriores requeridos para intervertir serían los mismos actos posesorios (antes previstos en el art. 2384 del C.Civ, y ahora en el art. 1915 CCCN), a los que define como hechos voluntarios que producen una modificación física sobre una cosa supuestamente poseída y que permiten llegar al convencimiento de haber estado en contacto con ella con ánimo de dueño. No estaríamos en presencia, para este autor, de institutos jurídicos distintos, sino de una única figura ${ }^{30 .}$

Entendemos que es posible sostener, si se toma como válida la definición de acto posesorio elaborada por dicha doctrina a partir del (hoy derogado) art. 2384 C.Civ, que estos “actos exteriores” de interversión no guardan relación de identidad con los actos posesorios, aunque puedan parecerse en gran medida.

Es que, como lo señalara Ventura en concordancia con la generalidad

29 "Nuestro Código [Civil del año 1869] adopta la doctrina de Savigny [...]" sostiene Musto, Néstor Jorge, cit. (n. 3), p. 174.

${ }^{30}$ Ventura, Gabriel, cit. (n. 19), p. 262. 
de la doctrina ${ }^{31}$, los actos posesorios se deben realizar en la cosa o sobre la cosa, y en general configuran siempre supuestos de actos materiales de ocupación (art. 2384 C.Civ.) Por ende, la conceptualización excluye conductas que no importen el ejercicio directo de un poder físico en o sobre la cosa.

Sostenemos que los actos exteriores, como elemento de la interversión, pueden materializarse en o sobre la cosa, pero también pueden consistir en otro tipo de conductas. Nos estamos refiriendo específicamente a la interposición de acciones legales en defensa de la posesión. Parece razonable afirmar que si un sujeto que accede a un inmueble en calidad de tenedor es despojado violentamente por un tercero y decide interponer acción en resguardo de su relación de poder que califica como posesoria, la promoción de este juicio podría tenerse por un acto exterior que manifieste la intención de privar al tercero poseedor de la disposición de la cosa. Y si la acción prosperase y la cosa le fuera finalmente restituida, es decir, si lograse la exclusión del agresor, sería difícil argumentar en contra de que se ha producido aquí una interversión de título.

Estas afirmaciones se hallan en línea con el pensamiento de Lafaille, quien ha señalado que la interversión puede consistir en actos judiciales que importen una rebelión contra el título actual y contra el sujeto a nombre de quien se ocupaba la $\operatorname{cosa}^{32}$. Peña Guzmán también coincide en que los actos de transmutación de título pueden manifestarse como actos judiciales, remarcando, sin perjuicio de ello, que la enorme mayoría de estas transmutaciones ocurren en sede extrajudicial ${ }^{33}$.

De los párrafos anteriores se desprende el interés práctico, y no puramente académico, de contar con una calificación adecuada de la figura. Si los actos exteriores fueran lisos y llanos actos posesorios, entonces los reclamos judiciales (o extrajudiciales) no podrían dar lugar a una interversión unilateral, aunque sean eficaces para superar una situación de despojo. En cambio, si se reconoce que los actos exteriores no guardan relación de identidad con los actos posesorios, sería válido aseverar que ciertas acciones judiciales tienen entidad suficiente para producir una interversión unilateral.

Un segundo interrogante surge en relación a la duración del fenómeno de la interversión.

${ }^{31}$ Papaño, Ricardo - Kiper, Claudio - Dillon, Gregorio - Causse, Jorge, cit. (n. 19), p. 52; Mariani de Vidal, Marina, cit. (n. 7), p. 138, entre otros.

${ }^{32}$ Lafaille, Héctor, Tratado de los Derechos Reales (Buenos Aires, Ediar, 1943) I, p. 135.

33 Peña Guzmán, Luis Alberto, Derechos Reales (Buenos Aires, TEA, 1975) I, p. 213. 
¿Se agota acaso en un solo acto? ¿Es una concatenación de actos que se realizan a lo largo de horas o días? ¿Podría prolongarse durante meses $\mathrm{o}$ años?

Normalmente el acto exterior que ocasione la privación será singular y no debería extenderse más allá de unos minutos: mediante un acto de violencia material o moral quien pretende intervertir repele los intentos del poseedor (o de su representante) de acceder a la cosa ocupada. El resultado sigue inmediatamente a la acción, sucede habitualmente en forma fugaz y, salvo denuncia ante autoridades policiales o judiciales formulada por el sujeto intervertido, la prueba de su ocurrencia no parece simple.

Además de estar concentrados en un único episodio, los actos exteriores también pueden consistir en un conjunto de preparativos tendientes a facilitar, con posterioridad, la exclusión del poseedor. Un sujeto que construye o mejora un muro perimetral, coloca nuevas puertas o portones de acceso, instala cerraduras o emplea candados u otros dispositivos para elevar el grado de seguridad con la expectativa de que, llegado el momento, será más sencillo rechazar las acciones del poseedor, es un sujeto que está en proceso de interversión. Bajo esta hipótesis, los actos exteriores podrían extenderse por días o semanas, y el proceso culminaría solo cuando se verifique la exclusión del afectado, la que posiblemente, al igual que en el caso anterior, será efímera y de difícil registro.

Como puede apreciarse en el somero análisis efectuado, contar con la prueba fehaciente de que se ha producido la interversión unilateral es harto difícil. Podría afirmarse que este alto grado de dificultad probatoria no es fortuito sino que el ordenamiento jurídico adrede pone las cosas verdaderamente arduas para los intervertores unilaterales, que son sujetos que adquieren su posesión habitualmente mediante conductas ilícitas, por lo que se justificaría privarlos de ventajas o facilidades en su camino hacia la usucapión.

Quienes admitan que los actos exteriores incluyen a los reclamos judiciales aceptarán que el proceso de intervención puede prolongarse mucho más allá de días y semanas, y estirarse tanto como dure el juicio correspondiente (habitualmente, 3 o 4 años). Una vez cumplida la sentencia favorable el actor habrá intervertido su título y contará además con las constancias del expediente para acreditarlo fehacientemente.

Una cuestión adicional es la que se refiere al rol que debe desempeñar el sujeto afectado por la interversión. La jurisprudencia ha reiterado que su relativo desinterés no basta para que se lo considere privado de la cosa, pero inferir de esta afirmación que la simple práctica de no concurrir jamás al inmueble del conflicto es un mecanismo legítimo para evitar que se concrete la efectiva exclusión no resulta razonable. Sería equiparable a 
otorgarle al afectado una suerte de poder de veto absoluto y perpetuo, o a premiar una negligencia supina.

Una vez que se reconoce que la interversión no puede quedar reducida al arbitrio absoluto del afectado deviene necesario preguntarse cómo y cuándo se podría producir el efecto exclusión en los supuestos en que este sujeto no sea expresamente repelido en su intento por acceder a la cosa.

Es probable que una respuesta satisfactoria pueda comenzar a elaborarse a partir de las normas sobre adquisición y pérdida de la posesión (art. 1923 in fine y $1931 \mathrm{CCCN}$ ), que sostienen que la relación de poder se adquiere con el apoderamiento de la cosa y se extingue cuando se pierde el poder de hecho sobre ella.

Con base en estos artículos, cuando una persona accede a una vivienda en carácter de tenedor, y luego de cierto tiempo, decide convertirse en poseedor y privar al "anterior" poseedor de la disposición de la cosa, y declara su voluntad en tal sentido, y además realiza actos materiales consecuentes (edifica un muro perimetral, coloca una nueva cerradura en la puerta de acceso, instala un sistema electrónico de monitoreo y alarma, u otros similares), podría sostenerse que ha adquirido la posesión de la cosa y, a la vez, que el anterior poseedor la ha perdido, aunque no trate de recobrarla por propia autoridad. Es posible, asimismo, que todas estas conductas del intervertor puedan graduarse en función de un "baremo de contradicción": cuanto más se opongan a la voluntad del afectado o a las condiciones normales de ejercicio de la relación de poder en análisis, mayor evidencia proporcionarán estas conductas a favor de que se ha producido una interversión de título, y viceversa.

Valga un ejemplo para aclarar la propuesta. El sujeto "A", en calidad de propietario y locador, celebra con 1 sujeto "B", en calidad de locatario, un contrato estándar de locación de inmueble por el plazo de 24 meses, sin facultades de inspección o acceso al bien por parte de "A", y sin facultades de introducir modificaciones materiales en la cosa ni de subarrendar a favor de "B".

Situación 1: "A" trata de ingresar al inmueble, sin consentimiento de "B", en el $7^{\circ}$ mes de vigencia del contrato, y es expulsado por "B". ¿Debe considerarse producida la interversión? Atento a que el locatario podría estar ejerciendo simplemente sus facultades de exclusión, pactadas previamente, esta exclusión ocuparía un lugar relativamente bajo o menor en el baremo de contradicción, sería una débil señal de interversión.

Situación 2: "B" efectúa importantes modificaciones materiales en la cosa, y luego la subarrienda a "C", quien modifica además del destino de la cosa, todo ello durante el décimo mes de vigencia del contrato. ¿Debe considerarse producida la interversión? En este escenario, la conducta 
del pretenso intervertor es abiertamente contradictoria a lo acordado con el afectado, y ostensiblemente incompatible con las condiciones en que normalmente debió haber ejercido la tenencia de la cosa. Las conductas descriptas se ubicarían en un punto relativamente alto del baremo de contradicción, ofreciendo fuertes indicios de interversión.

Este "baremo de contradicción" debería ser construido por el tribunal para cada caso, con ayuda de las partes, y utilizado para evaluar el conjunto de conductas del pretenso interversor. Sería de especial utilidad cuando no se produce o no se puede acreditar la ocurrencia de expulsión violenta del afectado. Entonces, a la interpretación acotada de que el poder de hecho se pierde únicamente cuando el afectado es privado "en persona" de la cosa, se contrapone el criterio más amplio de que la exclusión puede producirse también en forma "objetiva", cuando el sentido común y la experiencia indican que su relación de poder se ha extinguido, aunque el afectado no haya sufrido personalmente un acto concreto de repulsión.

El último punto que atenderemos en este trabajo es el de la prueba de la interversión. Con frecuencia los actos de expulsión se producirán en circunstancias que dificulten en extremo su acreditación, porque son temporalmente muy breves, o tiene lugar en zonas rurales o aisladas, sin testigos ni intervención de autoridades policiales ni judiciales, o mediante la construcción de mejoras compatibles con fines múltiples, entre otros factores.

Ahora, el hecho de que la acabada demostración de la interversión constituya generalmente una tarea laboriosa no debe ser causal de abandono de la figura ni de su desnaturalización, sino que debe constituir un llamado a agudizar el ingenio y repensar críticamente el sentido y los alcances del instituto.

Si no se puede probar el acto, por los motivos ya señalados, además del recurso al sugerido "baremo", una alternativa adicional tal vez sea la de probar la estela del acto, estela observable en las conductas desplegadas por las partes con posterioridad al supuesto suceso.

En este sentido, la búsqueda debería dirigirse en primer lugar a detectar actos de desapoderamiento expreso, y en subsidio, actos compatibles con un apoderamiento a título de poseedor, ostensibles y reiterados, que serían los rastros o huellas de la interversión. En esta última secuencia se trataría de localizar un hito, un punto en la trayectoria de conductas a partir del cual resulte altamente probable que la interversión ya se hubiese producido, señalarlo, fundar suficientemente la postura y tener por operada la figura. Todo ello sin perjuicio de la mantención del criterio de interpretación restrictiva en materia de interversión. 


\section{REFLEXIONES FINALES}

Los presupuestos, el contenido y los contornos de la interversión de título permanecen aún un tanto difusos en el ordenamiento argentino. Quizás esto se deba a su estrecho vínculo con una controversia extendida, profunda y antigua, la de la naturaleza de la posesión, y a que en alguna de sus clases, específicamente en la modalidad unilateral, la prueba de los hechos relevantes puede llegar a ser diabólica.

No obstante ello, si el sistema jurídico incorpora la figura de la interversión unilateral como un mecanismo reprochable en su origen pero de todos modos válido para acceder a la posesión y, posteriormente, a la usucapión, debe proveer los medios necesarios para que el instituto pueda cumplir su función y su finalidad.

Esto quiere decir que la consigna para los juristas, litigantes y magistrados es interpretar y aplicar la figura consagrada legislativamente de manera tal que tenga existencia real y no meramente ficticia o degradada, dotándola de una dinámica que le permita integrarse armónicamente al sistema de derecho civil en general y de derechos reales en particular.

En tal sentido el presente trabajo pretende aportar un conjunto de observaciones relativas a la naturaleza, los elementos, la extensión temporal y la prueba de la interversión unilateral, todas tendientes a mejorar la comprensión que tenemos de la figura y a facilitar su correcta aplicación.

\section{BIBLIOGRAFÍA}

Arean, Beatriz, Derechos Reales (6 $6^{\circ}$ edición, Bs. As., Hammurabi, 2003).

Arean, Beatriz, Juicio de Desalojo (1º edición, Bs. As., Hammurabi, 2004).

Borda, Guillermo, Tratado de Derecho Civil-Derechos Reales (2º edición, Bs. As., Perrot, 1978).

Causse, Federico y Pettis, Christian, en Herrera, Marisa, Caramelo, Gustavo y Picasso, Sebastián (directores), Código Civily Comercial de la Nación Comentado (1 ${ }^{\circ}$ edición, Bs. As., Infojus, 2015).

Clerc, Carlos, Derechos reales e intelectuales ( $1^{\circ}$ edición, Bs. As., Hammurabi, 2007).

CORNEjo, Américo, Interversión del título por el comodatario, en Revista La Ley (2013), E, 385.

FUSTER, Gabriel, La necesaria "re-significación" de la interversión de título. La dinámica funcional del corpus y el animus posesorios, en Revista La Ley Córdoba (2013), p. 1184.

Gschwind, Francisco, El constituto posesorio en el Código Civil Argentino, ahora, en AlteRINI Jorge Horacio (editor), Derecho notarial, registral e inmobiliario ( $1^{\circ}$ edición, Bs. As., La Ley, 2012).

Gurfinkel de Wendy, Lilian, Derechos Reales (2º edición, Bs. As., Abeledo Perrot, 2016). Kiper, Claudio, en LorenzetTi, Ricardo (director), Código Civily Comercial de la Nación Comentado (1 ${ }^{\circ}$ edición, Santa Fe, Rubinzal Culzoni, 2015).

Lafaille, Hector, Tratado de los Derechos Reales (sin edición, Bs. As., Ediar, 1943)

Mariani de Vidal, Marina, Derechos Reales (8 edición, Bs. As., Zavalía, 2009). 
Musto, Néstor Jorge, Derechos Reales (1ㅇ edición, $1^{\circ}$ reimpresión, Bs. As., Astrea, 2007). Papaño, Ricardo; Kiper, Claudio; Dillon, Gregorio y Causse, Jorge, Derechos Reales ( $3^{\circ}$ edición, Bs. As, Astrea, 2012).

Peña Guzmán, Luis Alberto, Derechos Reales (1º edición, Bs. As., TEA, 1975)

Perrotti, Pedro, Los Derechos Reales y la Teoría General de la Posesión (1º edición, Corrientes, Moglia, 2003).

Pettis, Christian y Rosembrock, Javier, en Bueres, Alberto (director), Código Civily Comercial de la Nación (1º edición, Bs. As., Hammurabi, 2014).

Ventura, Gabriel, La interversión de titulo, en Revista La Ley Córdoba (2001).

Jurisprudencia citada

Corte Suprema de Justicia de la Nación (Argentina), Sentencia del 3 de junio de 2014 dictada en autos "Mimica, Ricardo Juan y otro c/ Tierra del Fuego, Antártida e Islas del Atlántico Sur, Provincia de s/ Usucapión".

Corte Suprema de Justicia de la Nación (Argentina), Sentencia del 4 de mayo de 1993 dictada en autos "La Rinconada S.A. (en liquidación) c/ Estado Nacional s/ Nulidad de Resolución”.

Corte Suprema de Justicia de la Nación (Argentina), Sentencia del 7 de octubre de 1993 dictada en autos "Glastra S.A.C. e I. c/ Estado Nacional y otros s/ Prescripción Adquisitiva”.

Corte Suprema de Justicia de la Nación (Argentina), Sentencia del 11 de junio de 1962 dictada en autos "Cornet D’Hunval, Marcelo c/ Santa Cruz, la Provincia de s/ Posesión Treintañal".

Superior Tribunal de Justicia de la Provincia de Corrientes (Argentina), Sentencia del 27 de noviembre del 2008 dictada en autos "Rodríguez Adriano c/ Alberto Tránsito Savaresse s/ Reivindicación".

Fallo Plenario de la Cámara Nacional de Apelaciones de Paz (Capital Federal, Argentina) del 15 de septiembre de 1960 dictado en autos "Monti, Atilio, Sucesión c/ Palacios de Buzzoni, Danila Silvia s/ Desalojo. 